\title{
Validation of the Japanese Version of the Yale Food Addiction Scale 2.0 (J-YFAS 2.0)
}

\author{
May Thet Khine ${ }^{1}$, Atsuhiko Ota ${ }^{1, * \mathbb{D}}$, Ashley N. Gearhardt ${ }^{2}$, Akiko Fujisawa ${ }^{1}$, \\ Mamiko Morita ${ }^{3}$, Atsuko Minagawa ${ }^{3}$, Yuanying Li $^{1}$, Hisao Naito ${ }^{1}$ (D) and Hiroshi Yatsuya ${ }^{1}$ (D) \\ 1 Department of Public Health, Fujita Health University School of Medicine, 1-98 Dengakugakubo, \\ Kutsukake-cho, Toyoake, Aichi 470-1192, Japan; maythet7@gmail.com (M.T.K.); akifuji@fujita-hu.ac.jp (A.F.); \\ liyy@fujita-hu.ac.jp (Y.L.); naitoh@fujita-hu.ac.jp (H.N.); yatsuya@fujita-hu.ac.jp (H.Y.) \\ 2 Department of Psychology, University of Michigan, 2268 East Hall, 530 Church Street, \\ Ann Arbor, MI 48109, USA; agearhar@umich.edu \\ 3 Faculty of Nursing, Fujita Health University School of Health Sciences, 1-98 Dengakugakubo, \\ Kutsukake-cho, Toyoake, Aichi 470-1192, Japan; mamorita@fujita-hu.ac.jp (M.M.); \\ mina@fujita-hu.ac.jp (A.M.) \\ * Correspondence: ohtaa@fujita-hu.ac.jp; Tel.: +81-562-93-2453; Fax: +81-562-93-3079
}

Received: 9 February 2019; Accepted: 19 March 2019; Published: 22 March 2019

check for updates

\begin{abstract}
The Yale Food Addiction Scale 2.0 (YFAS 2.0) is used for assessing food addiction (FA). Our study aimed at validating its Japanese version (J-YFAS 2.0). The subjects included 731 undergraduate students. Confirmatory factor analysis indicated the root-mean-square error of approximation, comparative fit index, Tucker-Lewis index, and standardized root-mean-square residual were 0.065, 0.904, 0.880, and 0.048, respectively, for a one-factor structure model. Kuder-Richardson $\alpha$ was 0.78 . Prevalence of the J-YFAS 2.0-diagnosed mild, moderate, and severe FA was $1.1 \%, 1.2 \%$, and $1.0 \%$, respectively. High uncontrolled eating and emotional eating scores of the 18-item Three-Factor Eating Questionnaire (TFEQ R-18) $(p<0.001)$, a high Kessler Psychological Distress Scale score $(p<0.001)$, frequent desire to overeat $(p=0.007)$, and frequent snacking $(p=0.003)$ were associated with the J-YFAS 2.0-diagnosed FA presence. The scores demonstrated significant correlations with the J-YFAS 2.0-diagnosed FA symptom count $(p<0.01)$. The highest attained body mass index was associated with the J-YFAS 2.0-diagnosed FA symptom count $(p=0.026)$. The TFEQ R-18 cognitive restraint score was associated with the J-YFAS 2.0-diagnosed FA presence $(p<0.05)$ and symptom count $(p<0.001)$, but not with the J-YFAS 2.0-diagnosed FA severity. Like the YFAS 2.0 in other languages, the J-YFAS 2.0 has a one-factor structure and adequate convergent validity and reliability.
\end{abstract}

Keywords: food addiction; Japan; validation; Yale Food Addiction Scale 2.0

\section{Introduction}

The idea of food addiction (FA) is receiving increased interest [1]. Evidence is emerging that certain types of foods (e.g., highly processed foods with high levels of refined carbohydrates and/or added fat) may be capable of triggering addictive-like eating behaviors (e.g., loss of control, withdrawal, and cravings) in some individuals, which can lead to significant impairment or distress, [2,3]. Obesity and eating disorders such as bulimia nervosa (BN), binge eating disorders (BED), along with psychiatric disorders such as depression, posttraumatic stress disorder, attention-deficit hyperactivity disorder, have been reported as potential correlates with FA [4-6]. Relevant pharmacological findings have been reported. Highly processed sweetened and fatty foods trigger a rewarding effect through the release of dopamine [7]. Repeated eating of hyper-palatable food down-regulates the dopaminergic 
response, resulting in impulsive and compulsive responses to food cues [8]. Food craving-an intense desire to eat a specific food-activates the hippocampus, insula, and caudate nucleus, similar to drug craving [9]. On the other hand, there has been a lot of debate regarding the extent to which food can be addictive in the same way as drugs. Controversies exist, for instance, as to whether FA represents a specific construct as addiction that is distinct from other eating disorders, such as BED, and whether neurobiological changes underlying FA behaviors are sufficiently ascertained in humans $[10,11]$.

The Yale Food Addiction Scale (YFAS) is the most commonly used measure to assess FA, although FA is not included in the Diagnostic and Statistical Manual of Mental Disorders, 5th edition (DSM-5) [12] and controversy exists regarding its definition [11]. The original YFAS applies the DSM 4th edition (DSM-IV) diagnostic criteria for substance dependence to the consumption of highly palatable foods (e.g., chocolate, ice cream, and pizza) $[13,14]$. Later, the scale was replaced with the Yale Food Addiction Scale 2.0 (YFAS 2.0) in response to the revision of the Substance-Related and Addictive Disorders criteria in the DSM-5 [15]. The YFAS 2.0 additionally introduced the following four diagnostic criteria: craving, use despite interpersonal or social consequences, failure in role obligations, and use in physically hazardous situations. It also introduced a severity classification. The YFAS 2.0 is available not only in English but also in German, French, Italian, Spanish, and Arabic [16-20]. The YFAS 2.0 exhibits good internal consistency, as well as convergent, discriminant, and incremental validity [15-20]. Associations of the YFAS-diagnosed FA with obesity, eating disorders, and psychiatric disorders have been accumulated. The YFAS 2.0-defined FA prevalence is supposed to draw a J-shape curve according to body mass index (BMI): 3.3-15.8\% in healthy general populations [15-20], 17.2-47.4\% in obese population [16,21], and $15.0 \%$ in underweight population [21]. Women and patients with eating disorders (BN and BED) and mental disorders (depression, sleep disturbance, and general psychiatric status) were more likely to have FA diagnosed with the YFAS 2.0 [15,17-19].

The current study aimed to validate the Japanese version of YFAS 2.0 (J-YFAS 2.0). Scant evidence regarding FA is available in Asia. The previous version of YFAS was translated into Chinese [22,23] and Malay [24]. Using these questionnaires, researchers reported that a FA diagnosis was assigned to $6.9-9.2 \%$ of Chinese teenage students [22,23] and 10.4\% of Malay obese adults [24]. FA prevalence in Japan has not been reported so far, to the best of our knowledge. The YFAS 2.0 has not yet been translated into Asian languages. Development of the J-YFAS 2.0 enables examining the FA prevalence in Japan, comparing it with other countries and regions, and exploring the mechanism of FA. Referring to previous research [15-19], we hypothesized that (1) the J-YFAS has a one-factorial structure for the 11 J-YFAS 2.0 diagnostic criteria (structural validity); (2) underweight, overweight, obesity, uncontrolled and emotional eating, frequent desire to overeat, frequent snacking, and mood and anxiety disorders are associated with the J-YFAS 2.0-diagnosed FA (convergent validity); (3) cognitive restraint in eating is not associated with the J-YFAS 2.0-diagnosed FA (discriminant validity); and (4) the internal consistency is good for the 11 J-YFAS 2.0 diagnostic criteria (reliability).

\section{Subjects and Methods}

\subsection{Study Design}

We employed a cross-sectional design. All data were collected from a questionnaire survey. The present study was completed in accordance with the Declaration of Helsinki and the Ethical Guidelines for Medical and Health Research Involving Human Subjects established by the Ministry of Education, Culture, Sports, Science and Technology and the Ministry of Health, Labour and Welfare, Japan. We obtained the approval by the Ethics Review Committee of Fujita Health University, Japan (HM17-110 and HM18-155). All subjects provided their informed written consent for participation in the present study. 


\subsection{Subjects}

This study was conducted with a convenience sample of undergraduate students from a private medical and health science university in Japan. The authors (A.O., M.M., and A.M.) explained the study purpose and methods to the students in the classes. Paper-based questionnaires were then distributed. Of the 759 students to whom the questionnaires were distributed, 752 (99\%) were returned. Those who did not provide informed consent $(n=2)$ and who did not fully complete the J-YFAS 2.0 $(n=18)$ were excluded from the analysis. One student who replied to experience desire to overeat 50 times per week was excluded as this reply was a significant outlier. Consequently, we retained the remaining 731 students $(96 \%)$ as the subjects.

\subsection{J-YFAS 2.0}

As with the YFAS 2.0 [15], the J-YFAS 2.0 is a 35-item self-administered questionnaire (Table S1). It assesses food consumption during the past 12 months. A Likert-scale ranging from 0 (never) through 7 (every day) is employed as a response option for each item. The items assess clinical impairment/distress and the following 11 diagnostic criteria: (1) eating larger amounts for a longer period than intended (consumed more than intended); (2) persistent desire or repeated unsuccessful attempts to quit eating (unable to cut down or stop); (3) spending considerable time or activity obtaining or eating food or recovering from eating (great deal of time spent); (4) giving up or reducing important social, occupational, or recreational activities due to eating (important activities given up); (5) continued eating despite knowledge of adverse consequences (use despite physical/emotional consequences); (6) development of tolerance (tolerance); (7) characteristic withdrawal symptoms (withdrawal); (8) continued eating despite interpersonal or social problems (use despite interpersonal/social problems); (9) failure to fulfil major role obligation at work, school, and home due to eating (failure in role obligation); (10) eating even in physically hazardous situations (use in physically hazardous situations); and (11) craving, strong desire, or urge for certain foods (craving). Each item is scored dichotomously based on the threshold determined by the YFAS 2.0 validation paper [15]. If any item that corresponds to the diagnostic criteria or clinical severity meets the clinical threshold, this criterion is endorsed. There are two scoring methods: the symptom count and the diagnostic threshold. For the symptom count scoring method, the diagnostic criteria for which the subjects meet are summed together. For the diagnostic threshold, the clinically significant impairment/distress criterion has to be met and two or more diagnostic criteria have to be met. The J-YFAS 2.0 FA diagnostic severity is classified as mild (2-3 criteria met plus impairment/distress), moderate (4-5 criteria met plus impairment/distress), and severe (6-11 criteria met plus impairment/distress).

For the development of the J-YFAS 2.0, the original English YFAS 2.0 [15] was translated into Japanese by the three Japanese authors (A.O., A.F., and H.Y.) and back-translated into English by an external professional translator who had no previous knowledge of the YFAS 2.0. Discrepancies between the back-translation and the original were resolved by consensus amongst the three Japanese authors and an American author (A.N.G.), who developed the original YFAS 2.0. We added two food examples, wagashi (Japanese traditional confectionery) and instant noodles (as salty snacks), in the introductory part, considering that food preference in Japan differs from western countries.

\subsection{Variables for Convergent and Discriminant Validity}

\subsubsection{Body Mass Index (BMI)}

Each subject self-reported their current and highest attained BMI. The questionnaire included a table indicating BMI from the weights and heights so that the subjects could choose their BMI from the following options: $<16.0,16.0-16.9,17.0-18.4,18.5-22.9,23.0-24.9,25.0-29.9$, and $\geq 30.0 \mathrm{~kg} / \mathrm{m}^{2}$. No one chose $<16.0 \mathrm{~kg} / \mathrm{m}^{2}$ for their current or highest attained BMI.

It was reported that Japanese tended to under-report their body weights and the tendency was more prominent among those with high BMI than those with low BMI [25]. We arranged the 
categorical response options for BMI to minimize the shame that subjects may feel for self-reporting their actual BMI.

\subsubsection{Three-Factor Eating Questionnaire Revised 18-Item Version (TFEQ R-18)}

The TFEQ R-18 is a self-assessment tool used to measure the following three types of eating behaviors: Cognitive restraint, uncontrolled eating, and emotional eating [26]. Cognitive restraint is a control over food intake in order to influence body weight and body shape [26]. Uncontrolled eating is a tendency to overeat food with the feeling of being out of control [27]. Emotional eating is a tendency to eat in response to negative emotions [27]. The higher the score is, the greater the levels of cognitive restraint, uncontrolled eating, and emotional eating are. We chose the corresponding items for the current study from the Japanese version of the original 51-item TFEQ [28].

\subsubsection{Desire to Overeat}

No validated questionnaire was available in Japanese to evaluate binge eating frequency. Thus, we asked the frequency of desiring to overeat with a single question, "How many times per week did you feel you wanted to eat more even after eating quite a lot of food during the last two hours?" The subjects filled in the number of the times.

\subsubsection{Snacking Frequency}

A frequency of snacking (eating and drinking outside of breakfast, lunch, or dinner) was self-reported. No validated questionnaire was available in Japanese to evaluate the frequency of snacking. Thus, we developed a single question, "How many days per week are you snacking?" for this evaluation. The subjects chose one of the following options: none, 2-3 days, 4-5 days, and almost every day. The snack included foods and drinks that contained any calories. Zero-calorie drinks, such as coffee and tea without milk and sugar, and vitamin and mineral supplements were excluded from the snack.

\subsubsection{Kessler Psychological Distress Scale (K6)}

The Japanese version of K6 was used as an indicator of mood and anxiety disorders [29]. A K6 score of 13 or greater was regarded as having such disorders.

\subsection{Statistical Analyses}

Confirmatory factor analysis (CFA) was conducted to assess the one-factor structure for the 11 J-YFAS 2.0 diagnostic criteria. Clinically significant impairment/distress was not included in this CFA analysis. The model fit was evaluated with the root-mean-square error of approximation (RMSEA), comparative fit index (CFI), Tucker-Lewis index (TLI), and standardized root-mean-square residual (SRMR). For assessing the reliability, internal consistency was calculated for the 11 J-YFAS 2.0 diagnostic criteria with Kuder-Richardson's $\alpha$ (KR-20). Convergent and discriminant validity was examined with chi-square test, $t$-test, analysis of variance (ANOVA), and Spearman's rank correlation. We examined whether the current and highest attained BMI, TFEQ R-18 cognitive restraint, uncontrolled eating, and emotional eating scores, frequency of desire to overeat, snacking frequency, and K6 score were associated with the J-YFAS 2.0-diagnosed FA. Not only the presence and severity (mild, moderate, and severe) but also the symptom count was used as the J-YFAS 2.0-diagnosed FA index, given the small numbers of subjects diagnosed as having FA. We could not apply the chi-square test to examine the associations of BMI, high K6 score, and the snacking frequency with the J-YFAS 2.0-diagnosed FA severity, since more than $20 \%$ of all cells had an expected frequency of less than five. Effect size indices were calculated [30-32]. Subjects with missing responses were excluded from the corresponding analyses. SPSS version 23.0 (IBM, Armonk, NY, USA) and Amos Version 23.0 (IBM, Chicago, IL, USA) were used for statistical calculations. 


\section{Results}

\subsection{Subjects' Characteristics}

Most subjects were women $(78.5 \%, n=574)$ (Table 1$)$. The mean (standard deviation) age was 20.8 (1.8) years. The years and majors included fourth-year medical technology students, first- to fourth-year nursing students, and third-year medical students. Around $80 \%$ of the subjects reported normal-weight BMI, 18.5-24.9 kg/m².

Table 1. Subject characteristics $(n=731)$

\begin{tabular}{|c|c|}
\hline Characteristics & Frequency $(\%)$ or Mean (SD) \\
\hline \multicolumn{2}{|l|}{ Sex } \\
\hline Men & $156(21.3 \%)$ \\
\hline Women & $574(78.5 \%)$ \\
\hline Age (year) & $20.8(1.8)$ \\
\hline \multicolumn{2}{|l|}{ Years and Majors } \\
\hline Fourth-year medical technology students & $149(20.4 \%)$ \\
\hline First-year nursing students & $142(19.4 \%)$ \\
\hline Second-year nursing students & $132(18.1 \%)$ \\
\hline Third-year medical students & $111(15.2 \%)$ \\
\hline Fourth-year nursing students & $99(13.5 \%)$ \\
\hline Third-year nursing students & $98(13.4 \%)$ \\
\hline \multicolumn{2}{|l|}{ Current body mass index (BMI) $\left(\mathrm{kg} / \mathrm{m}^{2}\right)$} \\
\hline $16.0-16.9$ & $17(2.3 \%)$ \\
\hline $17.0-18.4$ & $108(14.8 \%)$ \\
\hline $18.5-22.9$ & $521(71.3 \%)$ \\
\hline $23.0-24.9$ & $57(7.8 \%)$ \\
\hline $25.0-29.9$ & $21(2.9 \%)$ \\
\hline 30 and above & $6(0.8 \%)$ \\
\hline \multicolumn{2}{|l|}{ Highest attained BMI $\left(\mathrm{kg} / \mathrm{m}^{2}\right) *$} \\
\hline $16.0-16.9$ & $3(0.4 \%)$ \\
\hline $17.0-18.4$ & $60(8.2 \%)$ \\
\hline $18.5-22.9$ & $493(67.4 \%)$ \\
\hline $23.0-24.9$ & $117(16.0 \%)$ \\
\hline $25.0-29.9$ & $51(7.0 \%)$ \\
\hline 30 and above & $7(1.0 \%)$ \\
\hline Kessler Psychological Distress Scale (K6) score & $4.6(4.5)$ \\
\hline 13 or greater & $45(6.2 \%)$ \\
\hline \multicolumn{2}{|c|}{ Three-factor Eating Questionnaire-R 18 (TFEQ R-18) score } \\
\hline Cognitive restraint & $37.0(20.2)$ \\
\hline Uncontrolled eating & $35.5(19.9)$ \\
\hline Emotional eating & $29.7(27.5)$ \\
\hline Desire to overeat & 0.5 (1.0) (Range: 0-7) \\
\hline \multicolumn{2}{|l|}{ Snacking frequency per week } \\
\hline None & $89(12.2 \%)$ \\
\hline $2-3$ days & $276(37.8 \%)$ \\
\hline $4-5$ days & $157(21.5 \%)$ \\
\hline Almost every day & $208(28.5 \%)$ \\
\hline \multicolumn{2}{|l|}{ J-YFAS 2.0-diagnosed food addiction (FA) } \\
\hline No FA & $707(96.7 \%)$ \\
\hline Mild FA & $8(1.1 \%)$ \\
\hline Moderate FA & $9(1.2 \%)$ \\
\hline Severe FA & $7(1.0 \%)$ \\
\hline
\end{tabular}

SD: standard deviation. There were missing responses for sex $(n=1)$, age $(n=1)$, current BMI $(n=1), \mathrm{K} 6(n=4)$, the TFEQ R-18 cognitive restraint $(n=8)$, uncontrolled eating $(n=12)$, and emotional eating $(n=2)$, desire to overeat $(n=1)$, and snacking frequency $(n=1) .{ }^{*}$ Highest attained BMI means the highest weight ever (when not pregnant) during the lifetime. 


\subsection{CFA and Internal Consistency}

The RMSEA, CFI, TLI, and SRMR were $0.065,0.904,0.880$, and 0.048, respectively. One diagnostic criterion (failure in role obligation) indicated a factor loading of 0.31 (Table 2). The other diagnostic criteria had factor loadings of 0.41 or higher. The KR-20 was 0.78 for the 11 diagnostic criteria.

Table 2. Diagnostic criteria of the Japanese version of the Yale Food Addiction Scale $2.0(n=731)$.

\begin{tabular}{|c|c|c|c|}
\hline Diagnostic Criteria & Met Criteria & Did Not Meet Criteria & Factor Loading \\
\hline Consumed more than intended & $82(11.2 \%)$ & $649(88.8 \%)$ & $0.57 * * *$ \\
\hline Unable to cut down or stop & $124(17.0 \%)$ & $607(83.0 \%)$ & $0.52 * * *$ \\
\hline Great deal of time spent & $30(4.1 \%)$ & $701(95.9 \%)$ & $0.45^{* * *}$ \\
\hline Important activities given up & $25(3.4 \%)$ & $706(96.6 \%)$ & $0.41^{* * *}$ \\
\hline Use despite physical/emotional consequences & $45(6.2 \%)$ & $686(93.8 \%)$ & $0.55^{* * *}$ \\
\hline Tolerance & $31(4.2 \%)$ & $700(95.8 \%)$ & $0.50 * * *$ \\
\hline Withdrawal & $90(12.3 \%)$ & $641(87.7 \%)$ & $0.62 * * *$ \\
\hline Use despite interpersonal/social problems & $98(13.4 \%)$ & $633(86.6 \%)$ & $0.54 * * *$ \\
\hline Failure in role obligation & $29(4.0 \%)$ & $702(96.0 \%)$ & $0.31^{* * *}$ \\
\hline Use in physically hazardous situations & $42(5.7 \%)$ & $689(94.3 \%)$ & $0.56^{* * *}$ \\
\hline Craving & $21(2.9 \%)$ & $710(97.1 \%)$ & $0.50 * * *$ \\
\hline Impairment/distress & $29(4.0 \%)$ & $702(96.0 \%)$ & \\
\hline
\end{tabular}

$* * * p<0.001$, calculated with confirmatory factor analysis.

\subsection{J-YFAS 2.0-Diagnosed FA Prevalence}

The mean J-YFAS 2.0-diagnosed FA symptom count was 0.84 (SD = 1.61; range $=0-11$ ). The proportions of the subjects who met the threshold for each diagnostic criterion ranged from $2.9-17.0 \%$ (Table 2). A total of 24 (3.3\%) subjects were regarded as having FA: 8 (1.1\%) received a mild, $9(1.2 \%)$ a moderate, and $7(1.0 \%)$ a severe FA diagnosis using the J-YFAS 2.0 (Table 1). All subjects who were diagnosed as FA with the J-YFAS 2.0 were women. Sex was significantly associated with the J-YFAS 2.0-diagnosed FA ( $p=0.004$, Fisher's Exact Test).

\subsection{Convergent and Discriminant Validity}

For convergent validity, neither the current nor the highest attained BMI was associated with the presence of J-YFAS 2.0-diagnosed FA (Table 3). The highest attained BMI was associated with the J-YFAS 2.0-diagnosed FA symptom count, while the current BMI was not (Table 4). The effect size was small for the association between the highest attained BMI and the J-YFAS 2.0-diagnosed FA symptom count-the $\eta^{2}$ was 0.02 . A high K6 score and snacking frequency were significantly associated with the J-YFAS 2.0-diagnosed FA presence and the J-YFAS 2.0-diagnosed FA symptom count (Tables 3 and 4 , respectively). TFEQ R-18 uncontrolled eating and emotional eating scores and desire to overeat were significantly associated with the J-YFAS 2.0-diagnosed FA presence, severity, and symptom count (Tables 5-7, respectively).

For discriminant validity, there was a significant association between the TFEQ R-18 cognitive restraint score and the J-YFAS 2.0-diagnosed FA presence (Table 5). Its effect size was small-the Cohen's d was 0.44 . There was no significant association between the cognitive restraint score and the J-YFAS 2.0-diagnosed FA severity (Table 6). We found a significant correlation between the cognitive restraint score and the J-YFAS 2.0-diagnosed FA symptom count (Table 7). Its Spearman's rank correlation coefficient was 0.143 . 
Table 3. Associations of body mass index (BMI), the Kessler Psychological Distress Scale (K6) score, and snacking frequency with the J-YFAS 2.0-diagnosed food addiction (FA) absence/presence.

\begin{tabular}{|c|c|c|c|c|c|}
\hline & $\begin{array}{l}\text { FA Absent } \\
\quad(n=707)\end{array}$ & $\begin{array}{l}\text { FA Present } \\
\quad(n=24)\end{array}$ & Chi-Square & $p$ Value & Effect Size $(V)$ \\
\hline \multicolumn{6}{|c|}{ Current BMI $\left(\mathrm{kg} / \mathrm{m}^{2}\right)$} \\
\hline $16.0-16.9$ & $16(94.1 \%)$ & $1(5.9 \%)$ & \multirow{6}{*}{1.421} & \multirow{6}{*}{0.922} & \multirow{6}{*}{0.04} \\
\hline $17.0-18.4$ & $105(97.2 \%)$ & $3(2.8 \%)$ & & & \\
\hline $18.5-22.9$ & $503(96.5 \%)$ & $18(3.5 \%)$ & & & \\
\hline $23.0-24.9$ & $55(96.5 \%)$ & $2(3.5 \%)$ & & & \\
\hline 25.0-29.9 & $21(100 \%)$ & $0(0 \%)$ & & & \\
\hline 30 and above & $6(100 \%)$ & $0(0 \%)$ & & & \\
\hline \multicolumn{6}{|c|}{ Highest attained BMI $\left(\mathrm{kg} / \mathrm{m}^{2}\right) *$} \\
\hline $16.0-16.9$ & $3(100 \%)$ & $0(0 \%)$ & \multirow{6}{*}{1.522} & \multirow{6}{*}{0.911} & \multirow{6}{*}{0.05} \\
\hline $17.0-18.4$ & $58(96.7 \%)$ & $2(3.3 \%)$ & & & \\
\hline $18.5-22.9$ & $478(97.0 \%)$ & $15(3.0 \%)$ & & & \\
\hline $23.0-24.9$ & $113(96.6 \%)$ & $4(3.4 \%)$ & & & \\
\hline 25.0-29.9 & $48(94.1 \%)$ & $3(5.9 \%)$ & & & \\
\hline 30 and above & $7(100 \%)$ & $0(0 \%)$ & & & \\
\hline \multicolumn{6}{|l|}{ K6 score } \\
\hline 12 or less & $665(97.5 \%)$ & $17(2.5 \%)$ & \multirow[t]{2}{*}{22.565} & \multirow[t]{2}{*}{$<0.001$} & \multirow[t]{2}{*}{0.18} \\
\hline 13 or greater & $38(84.4 \%)$ & $7(15.6 \%)$ & & & \\
\hline \multicolumn{6}{|c|}{ Snacking Frequency Per Week } \\
\hline None & $89(100 \%)$ & $0(0 \%)$ & \multirow{4}{*}{13.855} & \multirow{4}{*}{0.003} & \multirow{4}{*}{0.14} \\
\hline $2-3$ days & $272(98.6 \%)$ & $4(1.4 \%)$ & & & \\
\hline 4-5 days & $151(96.2 \%)$ & $6(3.8 \%)$ & & & \\
\hline Almost every day & $194(93.3 \%)$ & $14(6.7 \%)$ & & & \\
\hline
\end{tabular}

Chi-square test was used. The numbers of missing responses were as follows: current BMI $(n=1), \mathrm{K} 6$ score $(n=4)$, and snacking frequency $(n=1) .{ }^{*}$ Highest attained BMI means the highest weight ever (when not pregnant) during the lifetime.

Table 4. Associations of body mass index (BMI), the Kessler Psychological Distress Scale (K6) score, and snacking frequency with the J-YFAS 2.0-diagnosed food addiction (FA) symptom count $(n=731)$.

\begin{tabular}{|c|c|c|c|c|c|}
\hline & $\begin{array}{c}\text { FA } \\
\text { Symptom Count }\end{array}$ & $\begin{array}{c}\mathrm{F} / t \\
\text { Value }\end{array}$ & $p$ Value & $\underset{\text { Pairwise Difference }}{\text { Paince }}$ & Effect Size $\left(\eta^{2}\right) /(d)$ \\
\hline \multicolumn{6}{|l|}{ Current BMI $\left(\mathrm{kg} / \mathrm{m}^{2}\right)$} \\
\hline $16.0-16.9$ & $1.0(2.7)$ & \multirow{6}{*}{1.375} & \multirow{6}{*}{0.231} & & \multirow{6}{*}{0.01} \\
\hline $17.0-18.4$ & $0.6(1.2)$ & & & & \\
\hline $18.5-22.9$ & $0.8(1.6)$ & & & & \\
\hline $23.0-24.9$ & $1.1(1.8)$ & & & & \\
\hline 25.0-29.9 & $1.4(2.1)$ & & & & \\
\hline 30 and above & $1.3(1.5)$ & & & & \\
\hline \multicolumn{6}{|c|}{ Highest attained BMI $\left(\mathrm{kg} / \mathrm{m}^{2}\right)$ * } \\
\hline $16.0-16.9(1)$ & $0.7(0.6)$ & \multirow{6}{*}{2.555} & \multirow{6}{*}{0.026} & \multirow{6}{*}{$(2),(3),(4)<(5)$} & \multirow{6}{*}{0.02} \\
\hline $17.0-18.4(2)$ & $0.6(1.7)$ & & & & \\
\hline $18.5-22.9(3)$ & $0.8(1.6)$ & & & & \\
\hline $23.0-24.9(4)$ & $0.7(1.1)$ & & & & \\
\hline 25.0-29.9 (5) & $1.5(2.3)$ & & & & \\
\hline 30 and above (6) & $1.1(1.5)$ & & & & \\
\hline \multicolumn{6}{|l|}{ K6 score } \\
\hline 12 or less & $0.8(1.4)$ & \multirow{2}{*}{-3.060} & \multirow{2}{*}{0.004} & & \multirow{2}{*}{0.95} \\
\hline 13 or greater & $2.2(3.2)$ & & & & \\
\hline \multicolumn{6}{|c|}{ Snacking frequency per week } \\
\hline None (1) & $0.4(0.7)$ & \multirow{4}{*}{15.986} & \multirow{4}{*}{$<0.001$} & \multirow{4}{*}{$(1),(2)<(3),(4)$} & \multirow{4}{*}{0.06} \\
\hline 2-3 days (2) & $0.5(1.0)$ & & & & \\
\hline 4-5 days (3) & $1.0(1.9)$ & & & & \\
\hline Almost every day (4) & $1.4(2.1)$ & & & & \\
\hline
\end{tabular}

Analysis of variance (for BMI and snacking frequency) and $t$-test (for K6 score) were used. FA symptom counts are shown as mean (standard deviation). The numbers of missing responses were as follows: Current BMI $(n=1)$, K6 score $(n=4)$, and snacking frequency $(n=1)$. ${ }^{a}$ Pairwise differences were of $p<0.05$ (Bonferroni corrected). *

Highest attained BMI means the highest weight ever (when not pregnant) during the lifetime. 
Table 5. Associations of the 18-item Three-Factor Eating Questionnaire (TFEQ R-18) scores and frequency of desiring to overeat with the J-YFAS 2.0-diagnosed food addiction (FA) absence/presence.

\begin{tabular}{cccccc}
\hline & $\begin{array}{c}\text { FA Absent } \\
(\boldsymbol{n}=\mathbf{7 0 7})\end{array}$ & $\begin{array}{c}\text { FA Present } \\
(\boldsymbol{n}=\mathbf{2 4})\end{array}$ & $\begin{array}{c}\boldsymbol{t} \\
\text { Value }\end{array}$ & $\begin{array}{c}\boldsymbol{p} \\
\text { Value }\end{array}$ & Effect Size (d) \\
\hline Cognitive restraint & $36.7(20.1)$ & $45.7(21.7)$ & -2.097 & 0.036 & 0.44 \\
Uncontrolled eating & $34.5(19.1)$ & $64.1(23.1)$ & -7.246 & $<0.001$ & 1.54 \\
Emotional eating & $28.6(26.4)$ & $63.9(34.6)$ & -4.959 & $<0.001$ & 1.32 \\
Desire to overeat & $0.41(0.91)$ & $1.7(2.0)$ & -2.965 & 0.007 & 1.28 \\
\hline
\end{tabular}

$t$-test was used. TFEQ R-18 scores and frequency of desiring to overeat are shown as mean (standard deviation). The numbers of missing responses were as follows: TFEQ R-18 cognitive restraint, $n=8$ ( 7 from FA absent, 1 from FA present); uncontrolled eating, $n=12$ (11 from FA absent, 1 from FA present); emotional eating, $n=2$ (all from FA absent); and desire to overeat, $n=1$ (from FA absent).

Table 6. Associations of the 18-item Three-Factor Eating Questionnaire (TFEQ R-18) scores and frequency of desiring to overeat with the J-YFAS 2.0-diagnosed food addiction (FA) severity.

\begin{tabular}{|c|c|c|c|c|c|c|c|c|}
\hline & $\begin{array}{c}\text { FA Absent } \\
(n=707)\end{array}$ & $\begin{array}{c}\text { Mild FA } \\
(n=8)\end{array}$ & $\begin{array}{c}\text { Moderate FA } \\
\quad(n=9)\end{array}$ & $\begin{array}{c}\text { Severe FA } \\
\quad(n=7)\end{array}$ & $\begin{array}{c}\mathbf{F} \\
\text { Value }\end{array}$ & $\begin{array}{c}p \\
\text { Value }\end{array}$ & $\begin{array}{c}\text { Pairwise } \\
\text { Difference }^{\text {a }}\end{array}$ & $\begin{array}{c}\text { Effect Size } \\
\left(\eta^{2}\right)\end{array}$ \\
\hline Cognitive restraint & $36.7(20.1)$ & $43.1(17.8)$ & $48.6(24.3)$ & $45.2(25.6)$ & 1.56 & 0.197 & \multirow{3}{*}{$\begin{array}{c}1<2,3,4 \\
1<3,4 \\
1<3,4 \\
2<4\end{array}$} & 0.01 \\
\hline Uncontrolled eating & $34.5(19.1)$ & $56.0(24.5)$ & $62.5(20.5)$ & $75.1(23.2)$ & 18.80 & $<0.001$ & & 0.07 \\
\hline Desire to overeat & $0.4(0.9)$ & $0.6(1.2)$ & $1.8(1.5)$ & $2.7(2.9)$ & 19.53 & $<0.001$ & & 0.07 \\
\hline
\end{tabular}

Analysis of variance was used. TFEQ R-18 scores and frequency of desiring to overeat are shown as mean (standard deviation). The numbers of missing responses were as follows: TFEQ R-18 cognitive restraint, $n=8$ (7 from FA absent, 1 from Moderate FA); uncontrolled eating, $n=12$ (11 from FA absent, 1 from Moderate FA); emotional eating, $n=2$ (all from FA absent); and desire to overeat, $n=1$ (from FA absent). ${ }^{\text {a }}$ Pairwise differences were of $p<0.05$ (Bonferroni corrected). 1 = No FA, 2 = Mild FA, 3 = Moderate FA, 4 = Severe FA.

Table 7. Spearman's rank correlation coefficients among the J-YFAS 2.0-diagnosed food addiction (FA) symptom count, the 18-item Three-Factor Eating Questionnaire (TFEQ R-18) scores, and frequency of desiring to overeat $(n=731)$.

\begin{tabular}{|c|c|c|c|c|c|}
\hline & $\begin{array}{c}\text { FA } \\
\text { Symptom Count }\end{array}$ & Cognitive Restraint & Uncontrolled Eating & Emotional Eating & Desire to Overeat \\
\hline \multicolumn{6}{|l|}{ FA symptom count } \\
\hline Cognitive restraint & $0.143^{* * *}$ & & & & \\
\hline Uncontrolled eating & $0.403^{* * *}$ & $0.248^{* * *}$ & & & \\
\hline Emotional eating & $0.296 * * *$ & $0.258 * * *$ & $0.619^{* * *}$ & & \\
\hline Desire to overeat & $0.277^{* * *}$ & 0.039 & $0.449^{* * *}$ & $0.361^{* * *}$ & \\
\hline
\end{tabular}

\section{Discussion}

We examined the J-YFAS 2.0's properties in a sample of healthy undergraduate students in Japan. The J-YFAS 2.0 had a one-factor structure and adequate convergent validity and reliability, like the YFAS 2.0 in other languages [15-20], whereas our results were not the same as hypothesized with regard to the associations of BMI and cognitive restraint in eating with the J-YFAS 2.0-diagnosed FA. The J-YFAS 2.0-diagnosed FA prevalence was 3.3\% in our subjects. Similar findings were reported from Italian and Spanish young healthy samples [18,19].

A one-factor structure was confirmed for the J-YFAS 2.0, which is the same as for the English, German, French, Italian, and Spanish YFAS 2.0 [15-19]. Our findings did not strictly meet the Hu and Bentler criteria, i.e., RMSEA $\leq 0.06, \mathrm{CFI} \geq 0.95$, TLI $\geq 0.95$, and SRMR $\leq 0.08$ [33]. However, one or more of the four indices do not often meet the criteria [34]. The French version of the YFAS 2.0 showed a CFI of 0.887 and RMSEA of 0.083 [17]. There is the criticism that the Hu and Bentler criteria may be too stringent [35]. Our fit indices did not deviate substantially from the $\mathrm{Hu}$ and Bentler criteria. We thus retained the one-factor structure of the J-YFAS 2.0. Regarding the reliability of the J-YFAS 2.0, KR-20 was 0.78. This suggests the acceptable internal consistency of the J-YFAS 2.0. 
The J-YFAS 2.0-diagnosed FA prevalence was 3.3\% in this study. A similar prevalence was observed in other developed countries: Italy $(3.4 \%)$ and Spain $(3.3 \%)[18,19]$. The subjects' characteristics of these three studies bear some resemblance, which might account for the similar prevalence. They were mainly young (aged about 20) and normal-weight people. Like our study, the Italian study collected the subjects from a medical school. About $80 \%$ of the subjects were female in both the Spanish and our sample. On the other hand, a web-based survey found a much higher YFAS 2.0-diagnosed FA prevalence, 9.7\%, among German-speaking university students with the similar age and BMI [16]. This could imply that not only biological characteristics but also cultural differences are associated with YFAS 2.0-diagnosed FA, although it is possible that the web-based survey received considerable attention from those with FA and obtained their participation. Similar to previous reports in the U.S. [15] and Italy [18], women exhibited a significantly greater YFAS 2.0-diagnosed FA prevalence than men in our study. This suggests a sex difference in YFAS 2.0-diagnosed FA, which should be further investigated in future studies.

The YFAS 2.0-diagnosed FA prevalence was high in overweight, obese, and underweight people in the U.S., Germany, France, Italy, Spain, and Egypt [15-21]. Contrary to these findings, both the current and highest attained BMI did not demonstrate an explicit association with the J-YFAS 2.0-diagnosed FA in the present study. We only found that the subjects with the highest attained BMI of 25.0-29.9 had a greater J-YFAS 2.0-diagnosed FA symptom count than those with the highest attained BMI of 17.0-24.9. However, its effect size was small-the $\eta^{2}$ was only 0.02 . One possible reason for the finding might be the small numbers of our subjects with overweight, obesity, and extreme underweight. Current overweight and obesity were declared only by nearly $4 \%$ of the subjects. This reflected the fact that Japan has a much lower prevalence of overweight and obesity than other countries where the YFAS 2.0 has been validated [36]. Perhaps, some subjects in our study could have under-reported their BMI [37], although we arranged the categorical response options for BMI to minimize the shame that subjects may feel for self-reporting their actual BMI. Consequently, the low prevalence of overweight and obesity exerted a floor effect, diminishing the association between BMI, especially overweight and obesity, and the J-YFAS 2.0-diagnosed FA. Another possible reason is that the causes to affect BMI are multifactorial and different by region. We did not examine all causes that potentially affected BMI more strongly than FA. For instance, some researchers pointed out that social norms (pressure) might drive the young Japanese women's desire for slimming [38-40]. They could have more impact on BMI than FA among our subjects. Our subjects involved medical, nursing, and medical technology students. They must have a greater knowledge of health, nutrition, and exercise than the normal population, which may have skewed the association between BMI, especially the current BMI, and the J-YFAS 2.0-diagnosed FA. Development of the J-YFAS 2.0 improves the examination of FA in Japan where the prevalence of obesity is much lower than the western countries [36]. This may help elucidate our understanding of the impact of FA on body weight. Although FA was initially applied to understanding obesity, controversy remains over how much FA explains obesity $[10,11]$.

Other variables hypothetically related to the convergent validity of the J-YFAS 2.0 showed significant associations with the J-YFAS 2.0-diagnosed FA as we expected. The TFEQ R-18 uncontrolled eating and emotional eating scores and desire to overeat were associated with the J-YFAS 2.0-diagnosed FA presence, severity, and symptom count in our study, as hypothesized based on the previous studies [15-19]. One study limitation is that we could not assess binge eating itself which was positively and moderately associated with the YFAS-diagnosed FA [41]. However, our findings regarding the desire to overeat and snacking would suggest the relationship between compulsive eating and FA. A desire to overeat forms a part of binge eating. Highly processed sweetened foods, which has been reported to be potentially related to FA [42-44], are often chosen for snacking in Japan [45]. We found that a high $\mathrm{K} 6$ score, which implied mood and anxiety disorders, is associated with the presence and higher symptom count of the J-YFAS 2.0-diagnosed FA. Some previous studies showed associations of psychopathological disorders [19] and depressive symptoms [18] with the YFAS 2.0-diagnosed FA. 
A recent systematic review suggested a positive, moderate association of the YFAS-diagnosed FA with depression and anxiety [41]. Our finding was consistent with them.

Regarding the discriminant validity, we hypothesized that cognitive restraint in eating was a different entity from FA, referring to the idea that the YFAS 2.0 does not simply measure an intention and a failure to restrict food consumption [15,16]. Our findings exhibited an inconsistency in the association of cognitive restraint in eating with the FA presence, severity, and symptom count. In our sample, the association between cognitive restraint and the J-YFAS 2.0-diagnosed FA would not be so strong even if the association existed. Previous findings are also inconsistent regarding the association. It was reported in France and Italy that the YFAS 2.0-diagnosed FA was associated with a high level of cognitive restraint $[17,18]$. The Italian researchers mentioned the possibility that addictive-like eating and restricting food consumption could coexist in patients with anorexia nervosa [18]. We could not ascertain this possibility in our study since we did not examine whether the subjects suffered from anorexia. Further research would be necessary to examine the role of anorexia in the association between cognitive restraint and FA.

There are several limitations to the interpretation of our findings. First, the current study employed a convenience sample that was dominated by young, under- and normal-weight, female, healthy undergraduate students. For a generalization of the present findings, the J-YFAS 2.0 should be tested for different-age groups, obese individuals, and patients with eating disorders. Second, we were not able to include all kinds of validity and reliability. For instance, we did not address incremental validity and test-retest reliability. Third, we used our original questions to assess the desire to overeat and frequency of snacking. For instance, the Binge Eating Scale (BES) [46] and the Eating Behavior Patterns Questionnaire (EBPQ) [47] are the validated tools to evaluate binge eating and snacking, respectively. We did not use them since they were not translated into and validated in Japanese. This may limit the comparison of our results with the others. Finally, as FA has not yet been recognized in the DSM-5, we could not define the standard of psychiatrist-diagnosed FA.

As mentioned in the introduction, the conceptual construct of FA and the neurobiological changes underpinning it remain controversial $[10,11]$. Development of the J-YFAS 2.0 would facilitate research on FA in Japan where prevalence of overweight and obesity is much lower than the western countries [36]. This would contribute to specifying the conceptual construct of FA and the neurobiological changes related to FA.

\section{Conclusions}

The J-YFAS 2.0 had a one-factor structure and adequate convergent validity and reliability, like the YFAS 2.0 in other languages. Further studies are necessary to confirm the discriminant validity of the J-YFAS 2.0.

Supplementary Materials: The following are available online at http:/ / www.mdpi.com/2072-6643/11/3/687/s1, Table S1: The Japanese version of the Yale Food Addiction Scale 2.0 (J-YFAS 2.0) (written in Japanese).

Author Contributions: M.T.K., A.O., A.N.G., and H.Y. designed the study plan. A.O., A.N.G., A.F., and H.Y. translated the English YFAS 2.0 into Japanese. M.T.K., A.O., A.F., M.M., A.M., Y.L., H.N., and H.Y. collected the data. M.T.K., A.O., and H.Y. analyzed the data and drafted the manuscript. A.N.G., A.F., M.M., A.M., Y.L., and H.N. critically reviewed and approved the manuscript. A.O. and H.Y. obtained the fund.

Funding: This research was funded by Fujita Health University. The funder had no role in the design of the study, the collection, analyses, or interpretation of data, writing the manuscript, or the decision to publish the results.

Acknowledgments: Data collection and processing were supported by Shunsuke Omura, Nozomi Furukawa, Yukino Onuma, Sho Nakahama, and Keigo Yamada.

Conflicts of Interest: The authors declare no conflict of interest. The content does not present the official views of the affiliations to which the authors belong. 


\section{References}

1. Meule, A. Back by Popular Demand: A Narrative Review on the History of Food Addiction Research. Yale J. Biol. Med. 2015, 88, 295-302. [PubMed]

2. Schulte, E.M.; Smeal, J.K.; Gearhardt, A.N. Foods are differentially associated with subjective effect report questions of abuse liability. PLoS ONE 2017, 12, e0184220. [CrossRef] [PubMed]

3. Meule, A.; Hermann, T.; Kubler, A. Food addiction in overweight and obese adolescents seeking weight-loss treatment. Eur. Eat. Disord. Rev. J. Eat. Disord. Assoc. 2015, 23, 193-198. [CrossRef]

4. Meule, A.; Gearhardt, A.N. Five years of the Yale Food Addiction Scale: Taking stock and moving forward. Curr. Addict. Rep. 2014, 1, 193-205. [CrossRef]

5. Pursey, K.M.; Stanwell, P.; Gearhardt, A.N.; Collins, C.E.; Burrows, T.L. The prevalence of food addiction as assessed by the Yale Food Addiction Scale: A systematic review. Nutrients 2014, 6, 4552-4590. [CrossRef] [PubMed]

6. Brewerton, T.D. Food addiction as a proxy for eating disorder and obesity severity, trauma history, PTSD symptoms, and comorbidity. Eat. Weight Disord. 2017, 22, 241-247. [CrossRef]

7. Onaolapo, A.Y.; Onaolapo, O.J. Food additives, food and the concept of 'food addiction': Is stimulation of the brain reward circuit by food sufficient to trigger addiction? Pathophysiology 2018, 25, 263-276. [CrossRef]

8. Volkow, N.D.; Wise, R.A.; Baler, R. The dopamine motive system: Implications for drug and food addiction. Nat. Rev. Neurosci. 2017, 18,741-752. [CrossRef]

9. Pelchat, M.L.; Johnson, A.; Chan, R.; Valdez, J.; Ragland, J.D. Images of desire: Food-craving activation during fMRI. Neuroimage 2004, 23, 1486-1493. [CrossRef]

10. Ziauddeen, H.; Farooqi, I.S.; Fletcher, P.C. Obesity and the brain: How convincing is the addiction model? Nat. Rev. Neurosci. 2012, 13, 279-286. [CrossRef]

11. Fletcher, P.C.; Kenny, P.J. Food addiction: A valid concept? Neuropsychopharmacology 2018, 43, $2506-2513$. [CrossRef]

12. American Psychiatric Association (APA). Substance-related and addictive disorders. In Diagnostic and Statistical Manual of Mental Disorders (DSM-5), 5th ed.; APA, Ed.; APA: Arlington, VA, USA, 2013; pp. 481-589.

13. Gearhardt, A.N.; Corbin, W.R.; Brownell, K.D. Preliminary validation of the Yale Food Addiction Scale. Appetite 2009, 52, 430-436. [CrossRef]

14. American Psychiatric Association (APA). Substance-related disorders. In Diagnostic and Statistical Manual of Mental Disorders (DSM-IV), 4th ed.; APA, Ed.; APA: Arlington, VA, USA, 1994; pp. 175-272.

15. Gearhardt, A.N.; Corbin, W.R.; Brownell, K.D. Development of the Yale Food Addiction Scale Version 2.0. Psychol. Addict. Behav. 2016, 30, 113-121. [CrossRef] [PubMed]

16. Meule, A.; Müller, A.; Gearhardt, A.N.; Blechert, J. German version of the Yale Food Addiction Scale 2.0: Prevalence and correlates of 'food addiction' in students and obese individuals. Appetite 2017, 115, 54-61. [CrossRef] [PubMed]

17. Brunault, P.; Courtois, R.; Gearhardt, A.N.; Gaillard, P.; Journiac, K.; Cathelain, S.; Réveillère, C.; Ballon, N. Validation of the French Version of the DSM-5 Yale Food Addiction Scale in a Nonclinical Sample. Can. J. Psychiatry 2017, 62, 199-210. [CrossRef] [PubMed]

18. Aloi, M.; Rania, M.; Rodriguez Munoz, R.C.; Jimenez Murcia, S.; Fernandez-Aranda, F.; De Fazio, P.; Segura-Garcia, C. Validation of the Italian version of the Yale Food Addiction Scale 2.0 (I-YFAS 2.0) in a sample of undergraduate students. Eat. Weight Disord. 2017, 22, 527-533. [CrossRef] [PubMed]

19. Granero, R.; Jiménez-Murcia, S.; Gearhardt, A.N.; Agüera, Z.; Aymamí, N.; Gómez-Peña, M.; Lozano-Madrid, M.; Mallorquí-Bagué, N.; Mestre-Bach, G.; Neto-Antao, M.I.; et al. Validation of the Spanish Version of the Yale Food Addiction Scale 2.0 (YFAS 2.0) and Clinical Correlates in a Sample of Eating Disorder, Gambling Disorder, and Healthy Control Participants. Front. Psychiatry 2018, 9, 208. [CrossRef] [PubMed]

20. Fawzi, M.; Fawzi, M. Validation of an Arabic version of the Yale Food Addiction Scale 2.0. East. Mediterr. Health J. 2018, 24, 745-752. [CrossRef]

21. Hauck, C.; Weiß, A.; Schulte, E.M.; Meule, A.; Ellrott, T. Prevalence of 'Food Addiction' as Measured with the Yale Food Addiction Scale 2.0 in a Representative German Sample and Its Association with Sex, Age and Weight Categories. Obes. Facts 2017, 10, 12-24. [CrossRef] [PubMed] 
22. Zhao, Z.; Ma, Y.; Han, Y.; Liu, Y.; Yang, K.; Zhen, S.; Wen, D. Psychosocial Correlates of Food Addiction and Its Association with Quality of Life in a Non-Clinical Adolescent Sample. Nutrients 2018, 10, 837. [CrossRef]

23. Chen, G.; Tang, Z.; Guo, G.; Liu, X.; Xiao, S. The Chinese version of the Yale Food Addiction Scale: An examination of its validation in a sample of female adolescents. Eat. Behav. 2015, 18, 97-102. [CrossRef] [PubMed]

24. Swarna Nantha, Y.; Abd Patah, N.A.; Ponnusamy Pillai, M. Preliminary validation of the Malay Yale Food Addiction Scale: Factor structure and item analysis in an obese population. Clin. Nutr. ESPEN 2016, 16, 42-47. [CrossRef]

25. Anai, A.; Ueda, K.; Harada, K.; Katoh, T.; Fukumoto, K.; Wei, C.-N. Determinant factors of the difference between self-reported weight and measured weight among Japanese. Environ. Health Prev. Med. 2015, 20, 447-454. [CrossRef] [PubMed]

26. Karlsson, J.; Persson, L.O.; Sjöström, L.; Sullivan, M. Psychometric properties and factor structure of the Three-Factor Eating Questionnaire (TFEQ) in obese men and women. Results from the Swedish Obese Subjects (SOS) study. Int. J. Obes. 2000, 24, 1715-1725. [CrossRef]

27. Anglé, S.; Engblom, J.; Eriksson, T.; Kautiainen, S.; Saha, M.-T.; Lindfors, P.; Lehtinen, M.; Rimpelä, A. Three factor eating questionnaire-R18 as a measure of cognitive restraint, uncontrolled eating and emotional eating in a sample of young Finnish females. Int. J. Behav. Nutr. Phys. Act. 2009, 6, 41. [CrossRef]

28. Adachi, Y.; Fujii, K.; Yamagami, T. Responses regarding restrained eating on the Three-Factor Eating Questionnaire and weight loss. Jpn. J. Behav. Ther. 1992, 18, 140-148.

29. Furukawa, T.A.; Kawakami, N.; Saitoh, M.; Ono, Y.; Nakane, Y.; Nakamura, Y.; Tachimori, H.; Iwata, N.; Uda, H.; Nakane, H.; et al. The performance of the Japanese version of the K6 and K10 in the World Mental Health Survey Japan. Int. J. Methods Psychiatr. Res. 2008, 17, 152-158. [CrossRef]

30. Cohen, J. A power primer. Psychol. Bull. 1992, 112, 155-159. [CrossRef]

31. Volker, M.A. Reporting Effect Size Estimates in School Psychology Research. Psychol. Sch. 2006, 43, 653-672. [CrossRef]

32. Lakens, D. Calculating and reporting effect sizes to facilitate cumulative science: A practical primer for t-tests and ANOVAs. Front. Psychol. 2013, 4, 863. [CrossRef]

33. Hu, L.-T.; Bentler, P.M. Cutoff criteria for fit indexes in covariance structure analysis: Conventional criteria versus new alternatives. Struct. Equ. Model. 1999, 6, 1-55. [CrossRef]

34. Bagozzi, R.P.; Yi, Y. Specification, evaluation, and interpretation of structural equation models. J. Acad. Mark. Sci. 2012, 40, 8-34. [CrossRef]

35. Barrett, P. Structural equation modelling: Adjudging model fit. Pers. Individ. Dif. 2007, 42, 815-824. [CrossRef]

36. Yatsuya, H.; Li, Y.; Hilawe, E.H.; Ota, A.; Wang, C.; Chiang, C.; Zhang, Y.; Uemura, M.; Osako, A.; Ozaki, Y.; et al. Global Trend in Overweight and Obesity and Its Association With Cardiovascular Disease Incidence. Circ. J. 2014, 78, 2807-2818. [CrossRef] [PubMed]

37. Elgar, F.J.; Roberts, C.; Tudor-Smith, C.; Moore, L. Validity of self-reported height and weight and predictors of bias in adolescents. J. Adolesc. Health 2005, 37, 371-375. [CrossRef] [PubMed]

38. Takimoto, H.; Yoshiike, N.; Kaneda, F.; Yoshita, K. Thinness Among Young Japanese Women. Am. J. Public Health 2004, 94, 1592-1595. [CrossRef] [PubMed]

39. Hayashi, F.; Takimoto, H.; Yoshita, K.; Yoshiike, N. Perceived body size and desire for thinness of young Japanese women: a population-based survey. Br. J. Nutr. 2007, 96, 1154-1162. [CrossRef]

40. Smith, A.R.; Joiner, T.E. Examining body image discrepancies and perceived weight status in adult Japanese women. Eat. Behav. 2008, 9, 513-515. [CrossRef] [PubMed]

41. Burrows, T.; Kay-Lambkin, F.; Pursey, K.; Skinner, J.; Dayas, C. Food addiction and associations with mental health symptoms: A systematic review with meta-analysis. J. Hum. Nutr. Diet. 2018, 31, 544-572. [CrossRef]

42. Schulte, E.M.; Avena, N.M.; Gearhardt, A.N. Which foods may be addictive? The roles of processing, fat content, and glycemic load. PLoS ONE 2015, 10, e0117959. [CrossRef]

43. Gearhardt, A.N.; Davis, C.; Kuschner, R.; Brownell, K.D. The Addiction Potential of Hyperpalatable Foods. Curr. Drug Abuse Rev. 2011, 4, 140-145. [CrossRef] [PubMed]

44. Lindgren, E.; Gray, K.; Miller, G.; Tyler, R.; Wiers, C.E.; Volkow, N.D.; Wang, G.J. Food addiction: A common neurobiological mechanism with drug abuse. Front. Biosci. (Landmark Ed.) 2018, 23, 811-836. [CrossRef] [PubMed] 
45. Takeichi, H.; Taniguchi, H.; Fukinbara, M.; Tanaka, N.; Shikanai, S.; Sarukura, N.; Hsu, T.-F.; Wong, Y.; Yamamoto, S. Sugar intakes from snacks and beverages in Japanese children. J. Nutr. Sci. Vitaminol. (Tokyo) 2012, 58, 113-117. [CrossRef] [PubMed]

46. Gormally, J.; Black, S.; Daston, S.; Rardin, D. The assessment of binge eating severity among obese persons. Addict. Behav. 1982, 7, 47-55. [CrossRef]

47. Schlundt, D.G.; Hargreaves, M.K.; Buchowski, M.S. The Eating Behavior Patterns Questionnaire predicts dietary fat intake in African American women. J. Am. Diet. Assoc. 2003, 103, 338-345. [CrossRef] [PubMed] 